\title{
Aerodynamic characteristics of an ogive-nose spinning projectile
}

\author{
J LIJIN and T J S JOTHI*
}

Department of Mechanical Engineering, National Institute of Technology Calicut, Kozhikode 673601, India

e-mail: tjsjothi@nitc.ac.in

MS received 19 May 2016; revised 14 May 2017; accepted 7 September 2017; published online 16 April 2018

\begin{abstract}
This work experimentally investigates the Robins-Magnus effect on a 5-caliber spinning projectile at a low subsonic Mach number of 0.1 corresponding to a Reynolds number of $3.2 \times 10^{5}$ based on the model length. The model configuration tested was a cylinder with spherically blunt tangent ogive nose portion. The normal, axial and side force coefficients were obtained for various angles of attack $(\alpha)$ ranging from $0^{\circ}$ to $34^{\circ}$ with non-dimensional spin rates $(\Omega)$ of $0-0.05$. Results indicate that the side force coefficient increases with $\alpha$ up to a value of around $28^{\circ}$ and decreases thereafter. Interestingly, in the range of spin rates considered in the present study, normal and axial force coefficients are not affected due to spin. However, the side force coefficients are seen to increase with spin rates at higher $\alpha$. Flow visualization studies are demonstrated to explain the underlying mechanism behind the variation of these aerodynamic coefficients.
\end{abstract}

Keywords. Spinning projectile; spinning missile; Robins-Magnus force; aerodynamic coefficients.

\section{Introduction}

Stability is a significant factor for missile and rocket projectiles. Lack of adequate stability of systems results in failure of missions. Thrust misalignment and asymmetries in mass are considered as the common cause for stability problems. Misalignment in the nozzle-vehicle assembly creates an undesired sideways component of thrust, and the moment produced about the centre of gravity due to the undesired thrust can cause the projectile to depart from its trajectory. Many projectiles and munitions such as aerial bombs, mortar rounds, sounding rockets and various missiles are intentionally spun about their longitudinal axis in order to improve stability and accuracy [1]. Most of the distance in its trajectory, a spinning projectile moves with an angle of attack commonly called yaw of repose, which can be effectively utilized to increase the range of an artillery shell [2]. At smaller angles of attack, spin induces distortions in the boundary layer over the projectile body, while at higher angles it generates asymmetric vortices in the cross flow plane. These distortions and asymmetric vortices contribute to a component of force in a direction perpendicular to the angle of attack plane. The physical mechanism resulting in this lateral force is due to the Magnus effect [3]. Later, honouring the contribution made by the British engineer on the discovery of lift force of a spinning body, much ahead to Magnus, this effect is presently known as the Robins-Magnus force [4, 5]. At smaller angles of attack, uneven boundary layer

*For correspondence displacement thickness due to spin is the main contribution to the Robins-Magnus force. As angle of attack increases, the mechanism becomes more complex since the effect of lee side separation comes into picture. The spin causes significant changes in the symmetry of lee vortices. Numerous parameters such as boundary layer behaviour, angle of attack, spin rate, projectile fineness ratio, Reynolds number and Mach number affect the nature and magnitude of Robins-Magnus force. Various research experiments have been carried out in wind tunnels to quantify and analyse the nature of this force in different flow regimes, namely subsonic, transonic and supersonic flows. Platou [6] experimentally compared the Robins-Magnus force coefficients for 3.2- and 5-caliber bodies at lower angles of attack in the range of $0-5^{\circ}$. They showed the RobinsMagnus force to be linearly varying with angles of attack for smaller values. Further, the normal force $\left(F_{N}\right)$ was observed to be independent of spin rates. Regan and Horanoff [7] specifically developed a strain gauge balance that can measure the side force and normal force coefficients with precision. They measured the former having the magnitude of 0.04 and latter having the magnitude of 0.6, which is fifteen times the former value.

Martin and Ingram [8] investigated a 7-caliber tangentogive-shape-nosed projectile at $\alpha$ value of $15^{\circ}$. With the help of smoke flow photographs and hot wire measurements, they proposed Robins-Magnus force as a complex interaction between boundary layer and body vortices. Cayzac et al [3] investigated the Robins-Magnus effect both experimentally and numerically over a wide range of angle of attack up to $30^{\circ}$. This force was well predicted 
Sādhanā (2018) 43:63

computationally by RANS-LES hybrid methods in various flow regimes from subsonic to supersonic, and got validated with the experimental results up to $10^{\circ}$ angle of attack. Power and Iversen [9] contributed an analytical theory for Robins-Magnus force prediction of spinning bodies. They presented the non-linearity in force coefficients with the proposed theory. Numerous works, both theoretical and experimental, have been carried out to predict and compute the Robins-Magnus force [10-13]. The experimental investigations by Seginer and Ringel [14] and Fletcher [15] show the existence of negative Robins-Magnus force or the inversion of Robins-Magnus force at critical Reynolds numbers at lower spin rates. The combined effect of cross flow Reynolds number and angle of attack is given as the explanation for the occurrence of negative Robins-Magnus force. Luchuk and Sparks [16] carried out experiments with a 7-caliber army-navy spinner rocket. It was observed that the Robins-Magnus force coefficient increases nonlinearly for higher angles of attack. Importantly, they have shown the existence of a maximum side force coefficient for $\alpha$ in the range of $10-15^{\circ}$. Uselton and Carman [17] carried an experimental research on a 0.355 -scale model of the Apache sounding rocket in the Mach number range of 2-6 with a non-dimensional spin rate of 0.06 . They observed that the maximum side force coefficients were observed in the angle of attacks range of $6-8^{\circ}$. Klatt et al [18] performed the simulation studies using RANS for a 6.37-caliber projectile and compared to the experiments. The studies were carried out at the Reynolds number of $1.09 \times$ $10^{7}$ corresponding to Mach number 3. They observed the maximum Robins-Magnus force in the angle of attack range of $10-15^{\circ}$. Sturek et al [19] computationally investigated the effect of nose bluntness on Robins-Magnus forces of projectiles. They found that the Robins-Magnus effect is $15 \%$ greater for hemispherical nose shell than for sharp nose configuration at Mach number 3. The RobinsMagnus effect of a 6-caliber ogive cylinder at transonic velocity was investigated computationally by Nietubicz et al [20]. They predicted the components that contribute to this effect as a function of projectile's axial position.

This literature survey demonstrates the finite amount of work carried out in the field of spinning projectiles, and its effect on aerodynamic forces. It is evident that most of the works in the literature carried out are either for highly subsonic or supersonic flow cases, at higher spin rates. Further, it is observed that the wind tunnel experimental data at lower Reynolds number and higher angles of attacks were found to be scarce in the archives. To fill this lacuna in the literature, the authors got motivated to carry out experiments with afore-mentioned conditions that establish the main objective of this study. This paper is related to the wind tunnel experimental data on a 5-caliber spinning projectile for angles of attack ranging from $0^{\circ}$ to $34^{\circ}$ and different spin rates $(\Omega=0-0.05)$. Reynolds number chosen for the investigation is $3.2 \times 10^{5}$.

\section{Experimental methodology}

\subsection{Model description and tunnel test facility}

The projectile model used for wind tunnel experiments is shown in figure 1 . The model is a cylindrical body made of aluminium with a spherically blunted tangent-ogive nose in the front. The model is fabricated by $\mathrm{CNC}$ machining process with a high degree of super-finishing. The length of the model $\left(l_{B}\right)$ is $150 \mathrm{~mm}$ and the diameter $(d)$ is $30 \mathrm{~mm}$. The body fineness ratio of the model is $5\left(l_{B} / d=5\right)$ and nose fineness ratio is $1.26\left(l_{N} / d=1.26\right)$. The projectile coordinate system and spin direction are shown in figure $1 \mathrm{~b}$. The $X$-axis coincides with the longitudinal axis of the model and positive towards downstream. The $Z$-axis is perpendicular to longitudinal axis and is positive upwards. The $Y$-axis is positive towards the port side. The model is spun clockwise around the positive $X$-axis.

The experiments are conducted in the blow-down wind tunnel test facility at National Institute of Technology Calicut, which can be used for low subsonic applications. Wind is generated using a $20 \mathrm{HP}$ blower. The experimental set-up is shown in figure 2 . The cross-sectional dimensions of the test section are $210 \mathrm{~mm} \times 210 \mathrm{~mm}$. The range of speed that is obtained at the test section is from 0 to $40 \mathrm{~m} / \mathrm{s}$. In the current study, the experiments are performed at 34 $\mathrm{m} / \mathrm{s}$. The supporting structure of the model is made of a thin plate to ensure a minimal interaction with the flow and to make the flow smoothly pass over it (figure 2). Care has been taken to eliminate the forces generated due to the supporting structure and the DC motor connected to the projectile body. A Pitot tube and pressure tappings are used to find the velocity and pressure. In the upstream of the test section, a honeycomb mesh is provided to straighten the air flow and reduce large-scale turbulence, if any. The projectile is connected to a three-component strain gauge balance connected to a digital load indicator to measure the aerodynamics forces. Spin is induced to the model by using a DC motor attached to the model.

\subsection{Experimental procedure}

Experiments are conducted at a low subsonic Mach number of 0.1 corresponding to the Reynolds number of $3.2 \times 10^{5}$ based on model length. The model is placed at different values of angles of attack and different spin rates. The former is varied in the range of $0-34^{\circ}$, and the non-dimensional spin rates considered are $\Omega=0.03,0.04$ and 0.05 . At all these conditions, various aerodynamics forces such as lift, drag and side forces are measured using a threecomponent strain gauge balance connected to a digital load indicator as shown in figure 2. The lift and drag force components, and normal and axial force components, are shown in figure 3 . The obtained lift and drag forces are converted to the normal force $\left(F_{N}\right)$ and axial force $\left(F_{A}\right)$ 
(a)

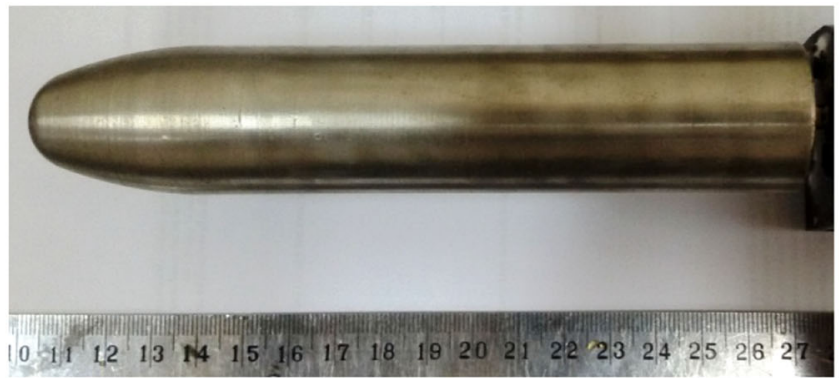

(b)

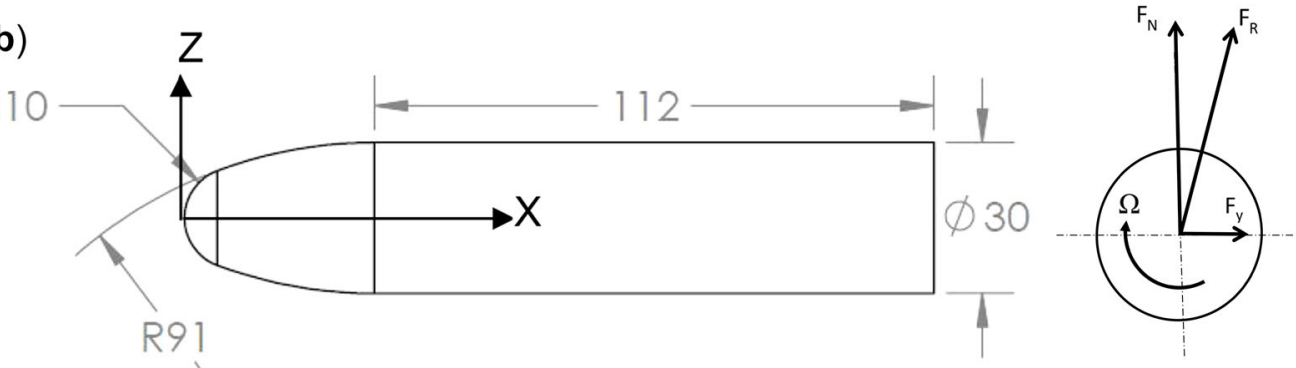

Figure 1. (a) Photograph and (b) dimensions of projectile geometry in $\mathrm{mm}$.

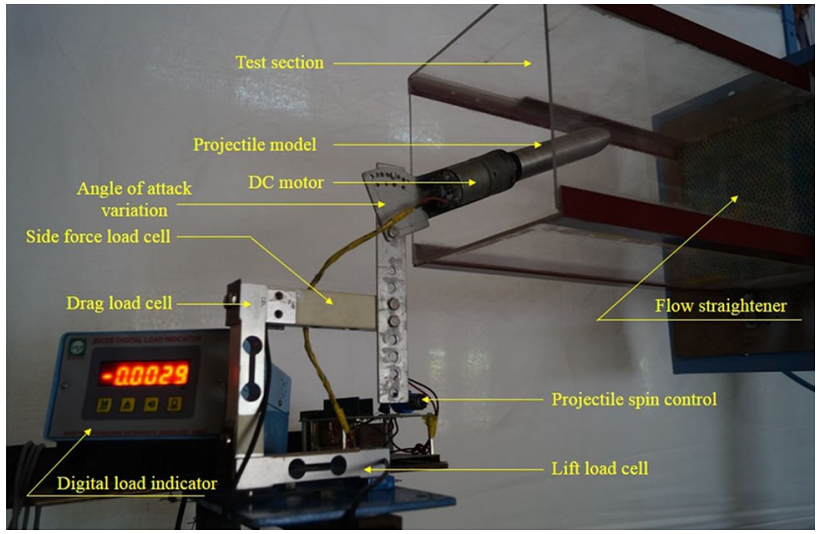

Figure 2. Photograph of the experimental set-up.

using the trigonometric relations as shown in Eq. (1) [21]. Sufficient time and care are taken to make the flow steady and free from any external disturbances.

$$
\begin{array}{r}
F_{N}=F_{L} \cos \alpha+F_{D} \sin \alpha, \\
F_{A}=-F_{L} \sin \alpha+F_{D} \cos \alpha .
\end{array}
$$

Flow visualization studies are carried out to investigate the flow physics qualitatively causing the Robins-Magnus force. A continuous green laser light source having power output of $8 \mathrm{~mW}$ is used to visualize the vortices. The laser light is converted to a sheet using a cylindrical lens and made to pass over the model perpendicular to flow direction. The laser sheet is illuminated using the commonly available magnesium silicate particles. The vortices behind the projectile are captured using a DSLR camera having a resolution of $1920 \times 1080$ pixels and an exposure time of $250 \mu \mathrm{s}$.

In the present study, the uncertainties and error estimates are described as follows. The velocity measurements are done using the Pitot static probe. The manometer measurements were carried with an accuracy of $\pm 1 \mathrm{~mm}$, and thus the velocity readings are expected to be uncertain within $\pm 0.3 \mathrm{~m} / \mathrm{s}$. The projectile spin is measured using a digital tachometer having an uncertainty of $\pm 2 \mathrm{rpm}$. The uncertainty associated with digital load cell indicator is $\pm 0.003 \mathrm{~kg}$.

\section{Results and discussion}

\subsection{Lift and drag forces on projectile}

Figure 4 shows the variation of lift and drag coefficients with angle of attack for spin rate of 0.04. The lift forces increase with angle of attack, establishing the fact that projectiles moving at larger angle of attack can travel larger trajectory [2]. The lift coefficient value increases from $C_{L}=$ 0 to 2 for $\alpha$ varying from $0^{\circ}$ to $34^{\circ}$, indicating an enormous increment in the lift forces at higher angles of attack. The increase of lift force coefficient seems to be almost linear after $3^{\circ}$ angle of attack. Contrastingly, the drag coefficient is almost constant $\left(C_{D} \approx 2\right)$ up to $15^{\circ}$ angle of attack and linearly increases to $C_{D}=3$ at $\alpha=34^{\circ}$. At lower angles of attack, since the flow is mostly attached to the body, the drag is due to the high skin friction, leading to constant drag forces at lower $\alpha$ values. However, at higher $\alpha$ value, the 


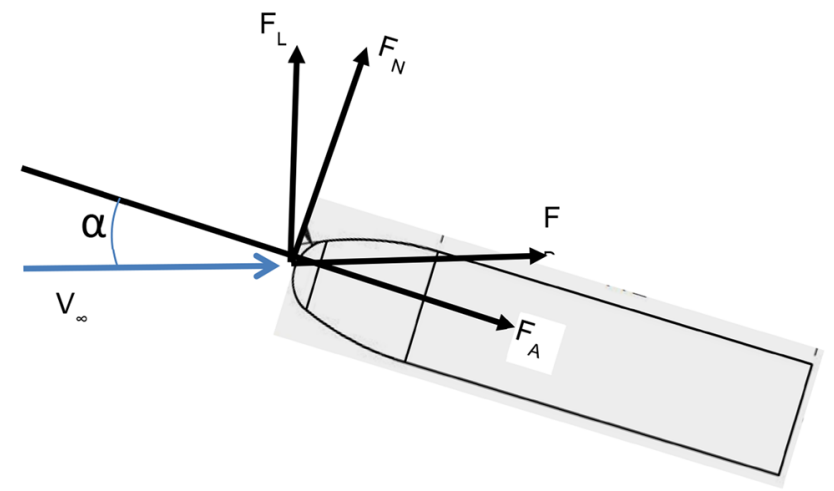

Figure 3. Indication of forces acting on projectile at angle of attack $\alpha$.

combined effect of separation due to nose bluntness and separation behind the cylinder body leads to higher pressure drag coefficients. It is observed from the figure that at all angles of attack the drag coefficient values are higher than the corresponding lift coefficients. However, the difference between the lift and drag coefficients seems to decrease with increase in angle of attack. It is important to note at this juncture that for an effective flight, higher values of lift to drag ratios are preferred. Figure 5 shows the ratio of lift to drag coefficients $\left(C_{L} / C_{D}\right)$ with angle of attack for different non-dimensional spin rates. This ratio is less than unity in the range of angle of attack considered. The positive gradient up to $\alpha \approx 30^{\circ}$ clearly suggests higher lift generation with increase in angle of attack. Further, from the plot in figure 5, the ratio becomes almost constant for angles of attack above $30^{\circ}$. Interestingly, the ratio of lift to drag coefficients did not show much variation with the spin rates as seen from figure 5. One of the reasons may be the lower spin rates, as its effect is not felt on this coefficients ratio.

\subsection{Normal and axial forces on projectile}

Figure 6 shows the variation of normal force coefficient with angle of attack for stationary $(\Omega=0)$ and spinning

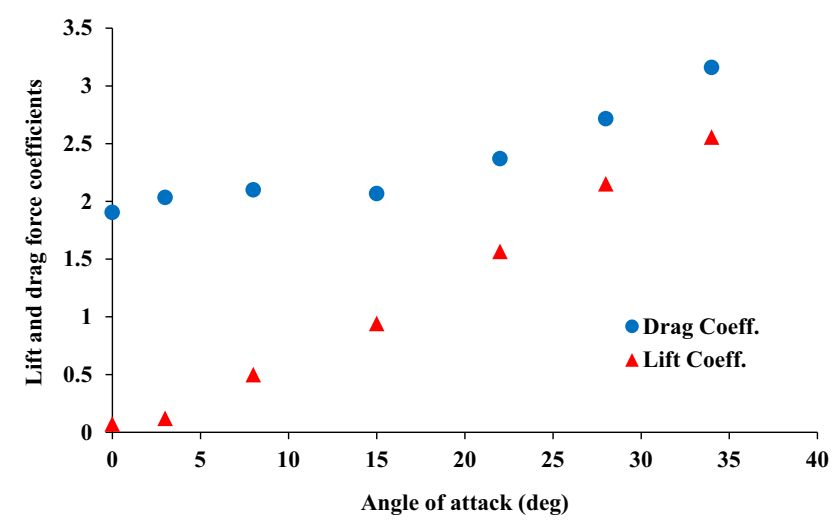

Figure 4. Variation of lift and drag coefficient with angle of attack for non-dimensional spin rate of $\Omega=0.04$. projectiles at different spin rates. The results indicate that normal force coefficient increases almost linearly with angle of attack. This is because the variation of normal force coefficient is associated with the asymmetric pressure distribution over the lee (top side of projectile) and wind side of projectile body. It is to be noted that this asymmetric distribution of pressure is a function of angle of attack, and thus $C_{N}$ is observed to increase with $\alpha$. This physics is better illustrated in figure $7 \mathrm{a}$, where an asymmetric pressure distribution is shown for a given angle of attack.

It is also observed that the normal force coefficients for a projectile at stationary and at different spin rates coalesce at all angles of attack, leading to an important conclusion that normal force coefficients are independent of spin rates, which is in congruence with the literature [18]. The reason for this may be cited as follows. In general, if a projectile is at zero angle of attack, the spin shifts the stagnation points of the projectile towards the spin direction. However, when angle of attack increases, the separation of vortices on lee side of projectile tends to become asymmetric due to spin. In the present case, the spin is presumed to shift the point of flow separation by a negligibly small value, thus making the spin rates insignificant on normal force coefficients. For better illustration, this flow physics is indicated in the form of a cartoon in figure 7 . It can be observed from the figure that in case of stationary projectile at higher $\alpha$, only normal- and axial forces act on the body, while for a spinning projectile, since the separation point gets shifted, a side force is also generated, which is generally termed a Robins-Magnus force $\left(F_{Y}\right)$. The separation points 1 and 2, shifting towards right for positive spin, can be observed from figure $7 \mathrm{~b}$. However, it is estimated that the normal forces are 10-15 times larger than the Robins-Magnus force [7], confirming the fact that side forces generated from the projectile models are too low. Additionally, it can be observed that the normal force coefficients and lift force coefficients have similar trend with angle of attack.

Figure 8 shows the variation of axial force coefficients $\left(C_{A}\right)$ with angle of attack for stationary $(\Omega=0)$ and

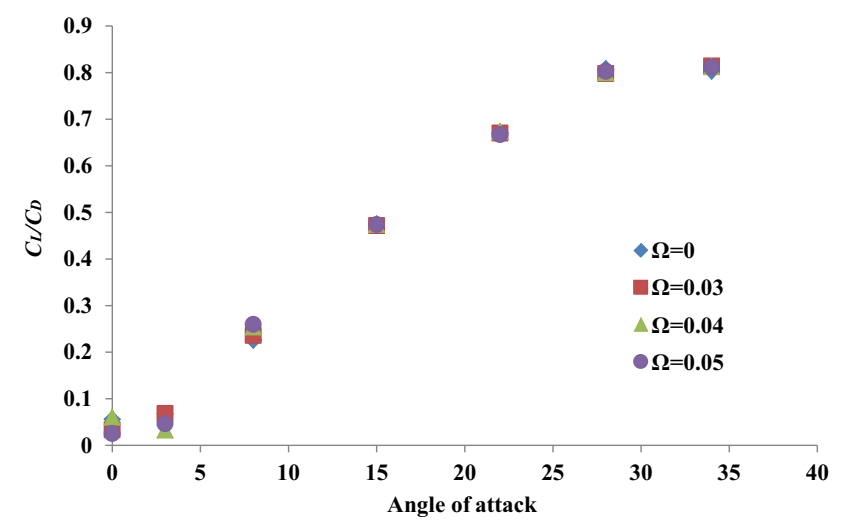

Figure 5. Variation of lift to drag coefficients ratio with angle of attack for different non-dimensional spin rates. 


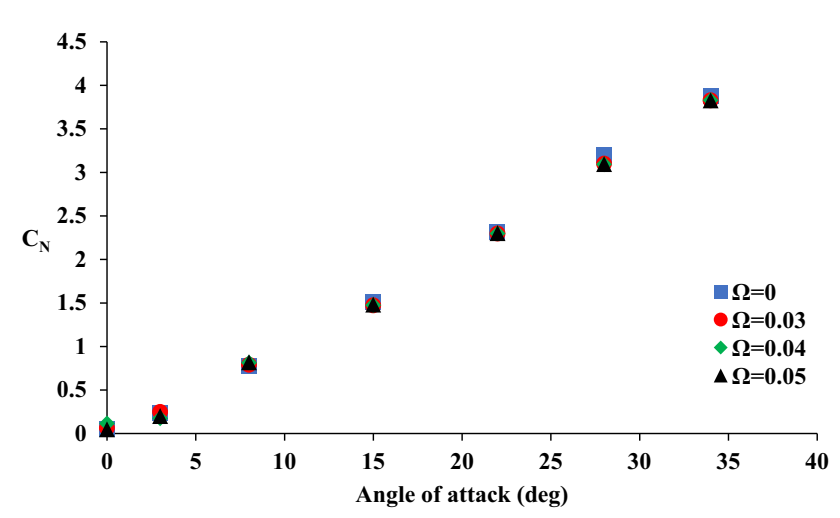

Figure 6. Normal force coefficient with angle of attack for different non-dimensional spin rates.
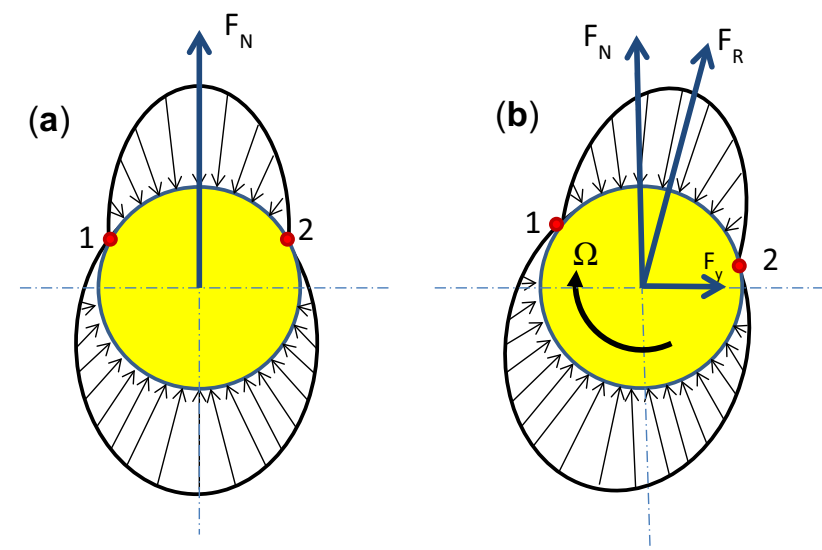

Figure 7. Cartoon showing the pressure distribution and forces acting on (a) stationary projectile and (b) spinning projectile along the cross-section of a projectile body inclined at $\alpha$.

spinning projectiles at different spin rates. The maximum value of $C_{A}$ is observed at lower angles of attack. This is because, at lower $\alpha$, the flow passes over the entire length of projectile without separation, and thus experiences maximum skin friction drag. However, up to the small angle of $5^{\circ}, C_{A}$ is seen to be increasing, which may be attributed to the effect of nose bluntness causing minor separations from the nose-cap. From the figure, a continuous decrement in $C_{A}$ values is observed with increase in the angle of attack. Since, from the discussion in the previous paragraph, it was concluded that projectiles at higher angles of attack lead to higher normal force components, the axial force components acting along the projectile are seen to be minimal as observed in figure 8 . Further, the axial force can be thought of as a projection of the drag force on the axis of the projectile; thus, it is seen to decrease with increase in the angle of attack. Interestingly, the drag force component that is along the flow direction is seen to increase (figure 4) while the axial force component, which is along the projectile, is seen to decrease with angles of attack. It is also clear from the figure that axial force coefficients are not affected by the projectile spin similar to normal force coefficients, and possibly for the same reasons as discussed in the previous paragraph.

\subsection{Influence of spin on side force}

Figure 9 shows the variation of side force coefficient with angle of attack at all spin rates. The data clearly indicate a linear increase of side force coefficients at lower angles of attack up to $8^{\circ}$. The reason for this behaviour is explained as follows: At lower angles of attack, the flow is presumed to be attached to the body, and is symmetric for considered free-stream velocity, and thus no separation occurs at lower angles of attack. As already explained in section 3.1, spin effect is confined to the boundary layer fluid in the projectile, and thus imparts an additional velocity to the boundary layer fluid. The resulting pressure imbalance due to spin generates a side force that varies linearly with smaller angles of attack. For angles of attack higher than $8^{\circ}$, side force coefficients increase non-linearly and reach a maximum. This is because, at higher angles of attack, the cross flow Reynolds number will be higher and the flow is no more attached to the projectile body [14]. This results in cross flow separation, and moreover the projectile spin introduces asymmetry in the vortices in the cross flow plane, which may be considered as the reason for nonlinear increase of side force coefficients at higher angles of attack. The maximum side force coefficients are found to be at $27-30^{\circ}$ angle of attack, where the maximum asymmetry in the vortices is expected along the cross flow plane. Beyond this value, the side force shows a decreasing trend that may be due to the complex interaction between the cross flow and the model spin. It is also to be noted that the higher cross flow Reynolds number creates secondary vortices [18]. It may be corroborated that the spin may be ineffective in shifting the separation point further down the spin direction, and the combined effect of primary- and secondary vortices reduces for angles of attack beyond $30^{\circ}$. Similar trends of increase in the side force coefficients to a

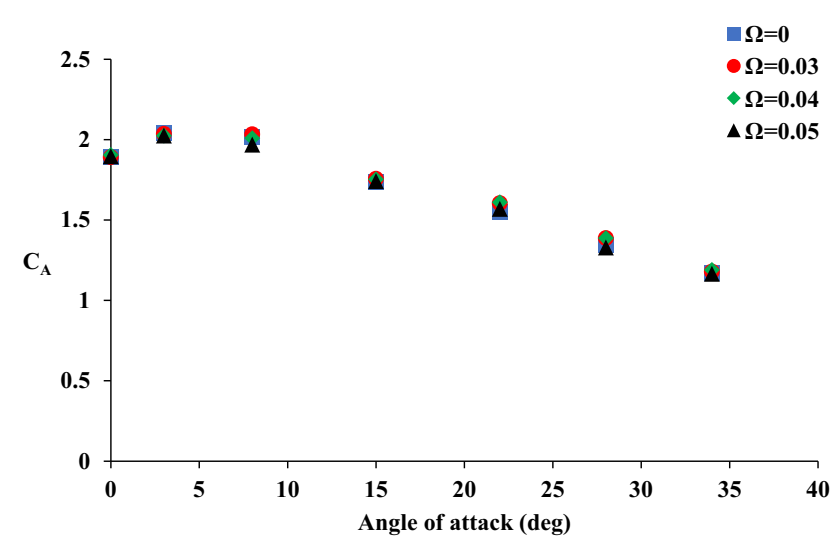

Figure 8. Axial force coefficient with angle of attack for different non-dimensional spin rates. 


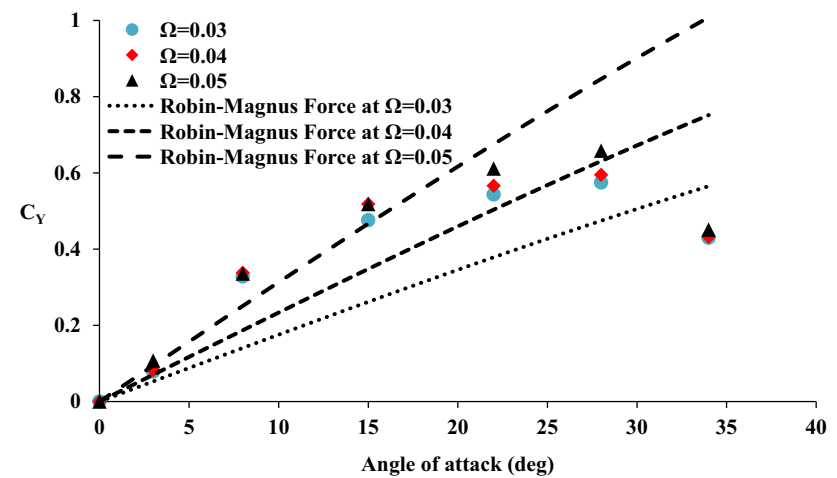

Figure 9. Variation of side force coefficient with angle of attack for different non-dimensional spin rates.

maximum value at a particular angle of attack and a decreasing trend thereafter are observed in the past literature [16, 17]. However, depending upon the flow Mach number/Reynolds number, the angle of attack corresponding to the maximum side force coefficients varies, which is elaborated in detail in the next section. Figure 9 also indicates the variation of side force coefficients with spin rates. It is observed that for angles of attack $15^{\circ} \leq \alpha \leq 30^{\circ}$, the side force coefficients marginally increase with spin rates. This may be attributed to the asymmetry in the flow separation along the cross flow plane of projectile. To corroborate this statement, flow visualization studies are carried along the cross flow plane to understand the flow separation from stationary and spinning projectiles, and shown in figure 10. The vortices are visualized at $\alpha=34^{\circ}$ and at an axial location of $2 d$ from the projectile base. In
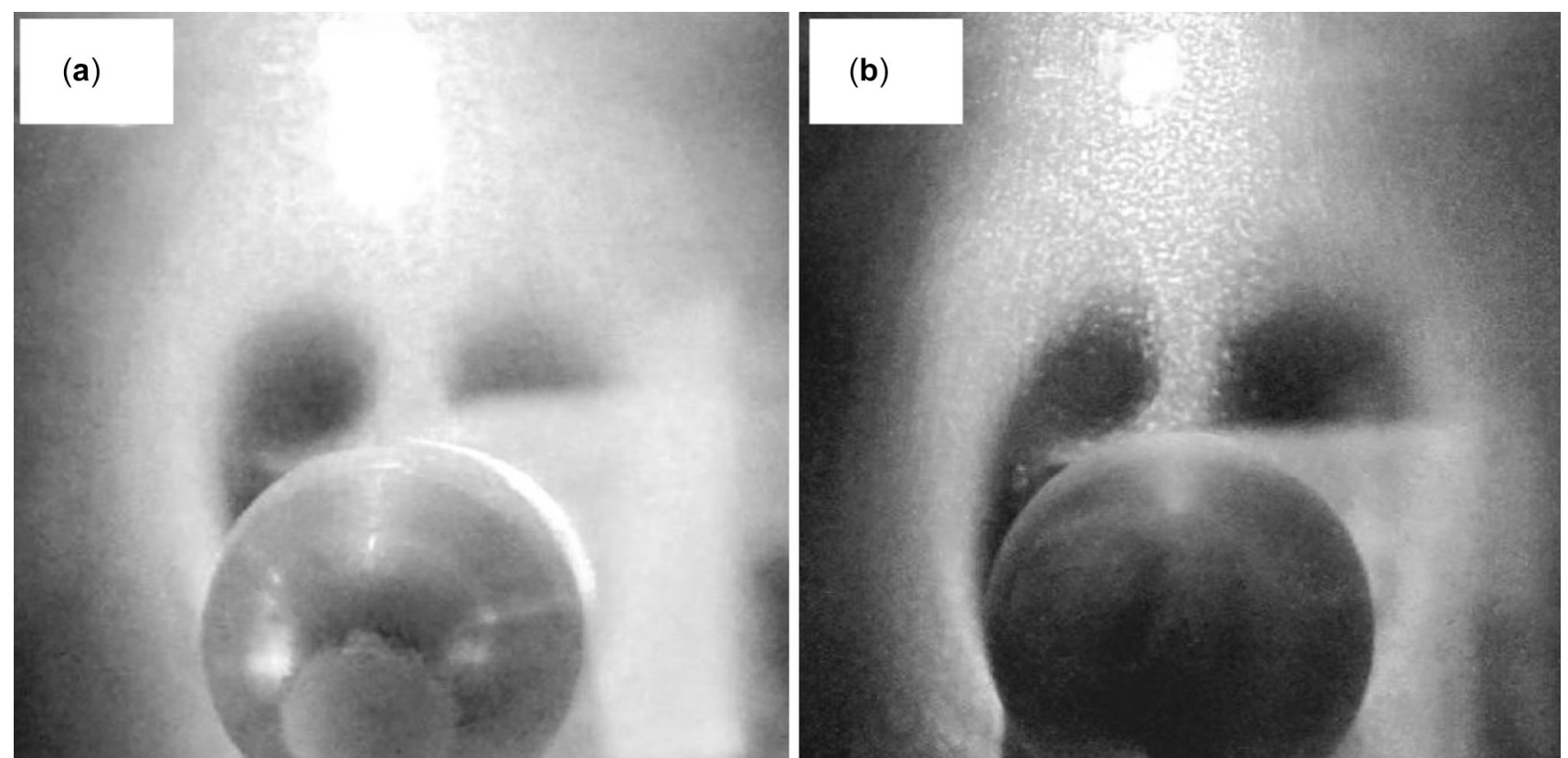

figure 10a, two symmetric vortices are observed, prompting the fact that no side forces act on the stationary projectile. However, in case of spinning projectile, two asymmetric vortices are observed (figure 10b), the left one being smaller in size compared with the right vortex. The figure qualitatively explains the separation points being shifted towards the spin direction, thus confirming the asymmetric behaviour of flow separation due to viscous effects. To make an effective comparison, the obtained forces that are due to viscous effects are compared to those due to the Robins-Magnus forces, which are due to the inviscid flow mechanism. The Robins-Magnus force is calculated using the relation $F_{y}=\rho V_{n \infty} \Gamma l_{b}$, which is the product of the flow density $(\rho)$, body normal component of free-stream velocity, circulation $(\Gamma)$ and projectile length $[4,21]$. The Robins-Magnus force coefficients at different angles of attack for different spin rates are plotted in figure 9. At zero angle of attack, the flow is symmetric over the projectile and thus no side forces are generated. As the angle of attack increase, these forces are observed to increase and reach a maximum when the projectile body is perpendicular to free-stream velocity vector. Since the Robins-Magnus forces are calculated using the inviscid flow theory, there is no flow separation and thus the side forces are seen to increase linearly. Also, with increase in the spin rates, the Robins-Magnus force coefficients are observed to increase due to the larger pressure imbalance on the projectile surface. At lower spin rates of $\Omega=0.03$ and 0.04, the observed side forces are higher than RobinsMagnus forces, which evidently indicates that the side forces are dominant due to the viscous effects of the flows at most of the angle of attacks, up to $\alpha \approx 30^{\circ}$. At the spin

Figure 10. Flow visualization: (a) showing the symmetric vortices in stationary projectile and (b) asymmetric vortices in case of spinning projectile. 
Table 1. Comparison of the occurrence of maximum side force from the literature.

\begin{tabular}{lccc}
\hline Reference & Projectile & Reynolds number & $\alpha$ value at maximum $C_{Y}($ deg $)$ \\
\hline Present study & Tangent-ogive shape with blunted nose & $3.2 \times 10^{5}$ & $27-30$ \\
Luchuk and Sparks [16] & Secant-ogive shape & $3.78-5.38 \times 10^{6}$ & $10-15$ \\
Klatt et al [18] & Tangent-ogive shape & $1.09 \times 10^{7}$ & $9-11$ \\
Uselton and Carman [17] & 0.355-scale model of Nike-Apache sounding rocket & $2.39 \times 10^{7}$ & $7-8$ \\
\hline
\end{tabular}

rate of $\Omega=0.05$, the obtained experimental results almost match the Robins-Magnus forces up to $\alpha=15^{\circ}$ and deviate thereafter.

The angles of attack corresponding to the maximum side force coefficients are compared to those in literature in table 1 for various conditions. Uselton and Carman [17] found the maximum side force at about $7-8^{\circ}$ angle of attack at $R e_{l}=2.39$ $\times 10^{7}$. Klatt et al [18] showed the maximum side force for angle of attack of $9-11^{\circ}$ at $1.09 \times 10^{7}$, which is slightly lower than that of the previous case. Luchuk and Sparks [16] showed the occurrence of maximum side force coefficients at 10-15 angle of attack for Reynolds number of $\mathrm{O}(6)$. As noted previously, the present study shows the maximum side force coefficient at $27-30^{\circ}$ for Reynolds number of $\mathrm{O}(5)$. This exercise results in an important conclusion that increase in the Reynolds number shifts the occurrence of the maximum side force towards lower angles of attack. This may be due to the combined effect of body fineness ratio and the cross flow velocity. However, this effect demands further investigation, which is beyond the scope of present work.

\section{Conclusion}

In this paper, the effect of spin on aerodynamic characteristics of a 5-caliber spherically blunted tangent-ogive projectile has been investigated by wind tunnel experiments. The investigation was carried out at a low subsonic Mach number of 0.1 with $\operatorname{Re}_{l}=3.2 \times 10^{5}$.

Results indicated that normal force components increased with angle of attack while the axial force components showed a decreasing trend due to the asymmetric pressure distribution over the lee and wind side of projectile body. Further, the role of spin on normal and axial force coefficients is found to be insignificant. The reason for this behaviour is attributed to negligible shift of flow separation points, and thus the change in pressure distribution over the projectile is not substantial due to spin.

Robins-Magnus force coefficients showed a non-linear increasing trend with angles of attack. This is due to the asymmetries induced by spin on cross flow vortices. Results also indicated that in the range of angles of attack $15^{\circ} \leq \alpha$ $\leq 30^{\circ}$, the side force coefficients marginally increase with spin rates, which is attributed to the asymmetric flow separation along the cross flow plane of projectile. Further analysis using flow visualization technique confirmed the presence of asymmetric vortices. The side force coefficients are found to be maximum in the angles of attack range of $27-30^{\circ}$. The angles of attack at which the side force coefficients are maximal are compared to those in literature, which led to an important conclusion that increase in the Reynolds number shifts the occurrence of the maximum side force towards lower angles of attack.

\section{Acknowledgement}

The authors would like to thank the anonymous reviewers for their valuable comments and suggestions for improving the manuscript.

\section{List of symbols}

$l_{B} \quad$ projectile length, $\mathrm{m}$

$d$ projectile diameter, $\mathrm{m}$

$l_{N} \quad$ projectile nose length, $\mathrm{m}$

A projectile cross-sectional area, $\mathrm{m}^{2}$

$F_{L} \quad$ lift, $\mathrm{N}$

$F_{D} \quad$ drag, $\mathrm{N}$

$F_{N}$ normal force, $\mathrm{N}$

$F_{A}$ axial force, $\mathrm{N}$

$F_{Y} \quad$ Robins-Magnus/side force, $\mathrm{N}$

$V_{\infty}$ free-stream velocity, $\mathrm{m} / \mathrm{s}$

$\rho$ density, $\mathrm{kg} / \mathrm{m}^{3}$

$q_{\infty} \quad$ dynamic pressure $\frac{\rho V_{\infty}^{2}}{2}, \mathrm{~Pa}$

$\mathrm{Re}_{l} \quad$ Reynolds number based on projectile length

$\alpha \quad$ angle of attack, deg

$p$ spin rate, $\mathrm{rad} / \mathrm{s}$

$\Omega \quad$ non-dimensional spin rate, $p d / 2 V_{\infty}$

$C_{N}$ normal force coefficient, $F_{N} / q_{\infty} A$

$C_{A} \quad$ axial force coefficient, $F_{A} / q_{\infty} A$

$C_{Y} \quad$ side force coefficient, $F_{Y} / q_{\infty} A$

$C_{L} \quad$ lift force coefficient, $F_{L / q_{\infty} A}$

$C_{D} \quad$ drag force coefficient, $F_{D} / q_{\infty} A$

\section{References}

[1] Seginer A and Rosenwasser I 1986 Magnus effect on spinning transonic finned missiles. J. Spacecr. Rockets 23(1): 31-38 
[2] Dupuis A and Berner C 2002 Wind tunnel tests of long range artillery shell concept. In: Proceedings of the AIAA Atmospheric Flight Mechanics Conference and Exhibit, Monterey, California

[3] Cayzac R, Carette E, Denis P and Guillen P 2011 Magnus effect: physical origins and numerical prediction. ASME J. Appl. Mech. 78(5): 051005-1-051005-7

[4] White F M 2011 Fluid mechanics, 7th ed. New Delhi: Tata McGraw Hill

[5] Sengupta T K and Talla S B 2004 Robins-Magnus effect: continuing saga. Curr. Sci. 86(7): 1033-1036

[6] Platou A S 1965 Magnus characteristics of finned and nonfinned projectiles. AIAA J. 3(1): 83-90

[7] Regan F J and Horanoff E V 1966 Wind tunnel Magnus measurements at the Naval Ordnance Laboratory. In: Proceedings of the AIAA Aerodynamic Testing Conference, California, AIAA Paper No. 66-753

[8] Martin J M and Ingram C W 1973 Experimental correlation between the flow and Magnus characteristics of a spinning ogive-nose cylinder. AIAA J. 11(7): 901-902

[9] Power H L and Iversen J D 1973 Magnus effect on spinning bodies of revolution. AIAA J. 11(4): 417-418

[10] Martin J C 1957 On Magnus effects caused by the boundarylayer displacement thickness on bodies of revolution at small angles of attack. J. Aeronaut. Sci. 24(6): 421-429

[11] Vaughn H R and Reis G E 1973 A Magnus theory. In: Proceedings of the 11th AIAA Aerospace Sciences Meeting, Washington, D.C., AIAA Paper No. 73-124

[12] Dwyer H A and Sanders B R 1975 Magnus forces on spinning supersonic cones - part 1: the boundary layer. In: Proceedings of the 13th AIAA Aerospace Sciences Meeting, California, AIAA Paper No. 75-193
[13] Sturek W B, Kayser L D, Nietubicz C J, Reklis R P, Opalka K O and Dwyer H A 1978 Computations of Magnus effects for a yawed, spinning body of revolution. AIAA J. 16(7): 687-692

[14] Seginer A and Ringel M 1983 Magnus effects at high angles of attack and critical Reynolds numbers. In: Proceedings of the AIAA Atmospheric Flight Mechanics Conference, Tennessee, AIAA Paper No-83-2145

[15] Fletcher C A J 1972 Negative Magnus forces in the critical Reynolds number regime. J. Aircr. 9(12): 826-834

[16] Luchuk W and Sparks W 1954 Wind-tunnel Magnus characteristics of the 7-caliber army-navy spinner rocket. NAVORD Technical Report No. 3813, U.S. Naval Ordnance Laboratory

[17] Uselton J C and Carman J B 1970 A study of the Magnus effects on a sounding rocket at supersonic speeds. In: Proceedings of the $8^{\text {th }}$ AIAA Aerospace Sciences Meeting, AIAA Paper No. 70-207

[18] Klatt D, Hruschka R and Leopold F 2013 Investigation of the Magnus effect of a generic projectile at Mach 3 up to 16 degrees angle of attack. ASME J. Appl. Mech. 80(3): 031603-1-031603-9

[19] Sturek W, Guidos B and Nietubicz C 1982 Navier-Stokes computational study of the Magnus effect on shell with small bluntness at supersonic speeds. In: Proceedings of the 9th AIAA Atmospheric Flight Mechanics Conference, California

[20] Nietubicz C J, Sturek W B and Heavey K R 1985 Computations of projectile Magnus effect at transonic velocities. AIAA J. 23(7): 998-1004

[21] Anderson Jr. J D 1984 Fundamentals of aerodynamics. New York: The McGraw-Hill Companies 